\title{
AVALIAÇÃO MULTICRITÉRIO DE DESEMPENHO O CASO DE UM TRIBUNAL DE JUSTIÇA
}

\author{
A MULTICRITERIA PERFORMANCE ANALYSIS: \\ THE CASE OF STATE SUPREME COURT \\ EVALUACIÓN DE DESEMPEÑO MULTICRITERIO \\ EL CASO DE UN TRIBUNAL DE JUSTICIA
}

\begin{abstract}
Resumo
A pesquisa desenvolveu um modelo de avaliação de desempenho alinhado aos interesses do gestor público e com o propósito de apoiar suas decisões. 0 contexto pesquisado corresponde a um setor administrativo e estratégico do Tribunal de Justiça de Santa Catarina (TJSC). A Metodologia Multicritério de Apoio à Decisão Construtivista (MCDA-C) foi o instrumento de intervenção adotado para a obtenção e análise dos dados, por possibilitar construir conhecimento no decisor a respeito do contexto que se propõe avaliar, a partir de sua prória percepção. Como resultados do estudo destacam-se: (i) o desenvolvimento de um modelo de avaliação de desempenho específico; (ii) a evidenciação de quatro Pontos de Vistas Fundamentais (PVF); (iii) a construção de seis descritores para o PVF "Gestão Interna", que abrangem aspectos compreendidos pelo decisor como relevantes sobre o tema; (iv) após a aferição do status quo dos indicadores, a identificação de que um dos indicadores da PVF "Gestão Interna" mereceria atuação premente; (v) a verificação de que 0 modelo construído permite subsidiar o gestor no processo de tomada de decisão no tocante à gestão do desempenho de seu setor; (vi) a viabilidade de replicar o procedimento para construção de modelo próprio para os demais setores que compõem 0 Tribunal de Justiça de Santa Catarina (TJSC).
\end{abstract}

Palavras-chave: Avaliação de desempenho, metodologia MCDA-C, Administração Pública, Tribunal de Justiça, Estado de Santa Catarina

Leonardo Ensslin - leonardoensslin@gmail.com

Professor da Universidade do Sul de Santa Catarina, Departamento de Ciências Sociais Aplicadas - Florianópolis - SC, Brasil

Ademar Dutra - ademar.unisul@gmail.com

Professor da Universidade do Sul de Santa Catarina, Departamento de Ciências Sociais Aplicadas - Florianópolis - SC, Brasil

Sandra Rolim Ensslin - sensslin@gmail.com

Professora da Universidade Federal de Santa Catarina, Departamento de Ciências Contábeis - Florianópolis - SC, Brasil

Anna Claudia Krüger - annakruger@gmail.com

Mestre em Administração pela Universidade do Sul de Santa Catarina - Florianópolis - SC, Brasil

André Antônio Gavazini - gavazini@yahoo.com.br

Analista jurídico no Tribunal de Justiça do Estado de Santa Catarina - Florianópolis - SC, Brasil

Submetido 13.04.2016. Aprovado 05.12.2016

DOI: http://dx.doi.org/10.12660/cgpc.v22n71.60544 


\section{Abstract:}

The present study has developed a model of performance evaluation that is both aligned with the interests of public administrators and able to support their decisions. The studied context is a strategic administrative sector of the Supreme Court of the State of Santa Catarina (TJSC), Brazil. Data were obtained and analyzed using the Multicriteria Decision Aid - Constructivist (MCDA-C) methodology as it allows decision makers to build knowledge about the context they are addressing based on their perception. The results of the study include: (1) the development of a specific performance evaluation model; (ii) the presentation of four Fundamental Viewpoints (PVFS); (iii) six Internal Management PVF indicators covering aspects that decision makers consider relevant; (iv) that urgent action is required regarding one of the Internal Management PVF indicators; (v) that the model we built can aid managers in their decision making process concerning performance management in their sector; (vi) the feasibility of replicating the procedure to build a suitable model for the other sectors forming the TJSC. Keywords: Performance evaluation, MCDA-C methodology, Public Administration, State Supreme Court, Santa Catarina State.

\section{Resumen}

La investigación ha desarrollado un modelo de evaluación de desempeño alineado con los intereses del gestor público y capaz de apoyar sus decisiones. El contexto investigado corresponde a un sector administrativo y estratégico del Tribunal de Justicia de Santa Catarina - TJSC. La Metodología Multicriterio de Apoyo a la Decisión Constructivista (MCDA-C) fue el instrumento de intervención adoptado para la recogida y análisis de datos, por permitir construir conocimiento en el decisor acerca del contexto que se propone evaluar, a partir de su propia percepción. Como resultados del estudio se destacan: (i) el desarrollo de un modelo de evaluación de desempeño específico; (ii) la revelación de cuatro Puntos de Vista Fundamentales (PVF); (iii) la construccion de seis descriptores para el PVF "Gestión Interna", que abarcan aspectos considerados por el decisor como relevantes para el tema; (iv) después de la determinación del status quo actual de los indicadores, la identificación de que uno de los indicadores del PVF "Gestión Interna" merecería una acción urgente; (v) la verificación de que el modelo construido permite apoyar al gestor en el proceso de toma de decisión referente a la gestión de desempeño de su sector; (vi) la factibilidad de replicar el procedimiento para la construcción de un modelo propio para los demás sectores que conforman el TJSC.

Palabras clave: Evaluación de desempeño, metodología MCDA-C, Administración Pública, Tribunal de Justicia, Estado de Santa Catarina.

\section{INTRODUÇÃO}

A Administração Pública vem sendo pressionada a proporcionar soluções imediatas para problemas urgentes, bem como fornecer mais e melhores serviços aos cidadãos brasileiros (Motta, 2013). Embora, a partir da década de 1930, tenham sido buscadas reformas no aparato administrativo com vistas a evitar a utilização de bens públicos em prol de interesses privados (Filgueiras, 2009), as instituições democráticas permanecem sendo objeto de ampla e continuada desconfiança dos cidadãos brasileiros (Moisés, 2005).

Diante disso, especialmente nas últimas duas décadas, tem sido exigido dos gestores públicos o melhor uso dos recursos públicos, além de uma atuação empreende- dora de Estado. Do administrador público espera-se, portanto, uma atuação voltada para o cidadão como cliente e o foco em uma gestão por resultados (Catelli \& Santos, 2004).

Destarte, a avaliação de desempenho passa a ser compreendida como essencial para a verificação da eficiência da atuação dos gestores públicos (Catelli \& Santos, 2004). Ademais, apresenta-se como instrumento de gestão que possibilita a evidenciação dos fatores críticos para o sucesso, possibilitando a organização, mensuração e monitoração deles, permitindo identificar com clareza os pontos fortes e fracos na organização e, por conseguinte, a alocação mais transparente e eficiente dos recursos (Ensslin, Montibeller, \& Noronha, 2001).

Para este estudo, conceitua-se a avaliação 
de desempenho, por meio de abordagem construtivista, como um instrumento de apoio à decisão a ser adotado quando há necessidade de expandir o entendimento do decisor acerca de seu contexto decisório e das consequências de suas decisões em cada um de seus objetivos estratégicos, táticos e operacionais, individual e global, contemplando a geração de ações de aperfeiçoamento em um processo contínuo de gestão (Ensslin, Giffhorn, Ensslin, Petri, \& Vianna, 2010).

Dessa forma, infere-se que a adoção de um modelo construtivista de avaliação de desempenho no setor público pode propiciar informações a serem aproveitadas para o apoio à tomada de decisão pelo decisor, proporcionando uma gestão mais eficiente dos recursos públicos.

O contexto físico objeto do estudo de caso corresponde a um setor vinculado ao Gabinete da Presidência do Tribunal de Justiça de Santa Catarina (TJSC) denominado Assessoria de Planejamento (Asplan). O referido setor é responsável pelo fomento à gestão estratégica da instituição, por meio de métodos, técnicas e ferramentas de gestão e de avaliação de desempenho aptos a operacionalizar a estratégia organizacional. Além disso, é composto pelo Coordenador de Planejamento e por oito Assessores de Planejamento.

Esse setor foi escolhido diante do interesse demonstrado pelo decisor do contexto pesquisado em dispor de um instrumento de gestão apto a avaliar o desempenho do setor e indicar os aspectos merecedores de atenção, como forma de priorizar os escassos recursos disponíveis.
Destaca-se, ainda, que o interesse do gestor é essencial ao sucesso do projeto, pois sua participação é fator inerente à adoção da metodologia construtivista de avaliação de desempenho, como será evidenciado na seção relativa aos resultados da pesquisa.

A importância do tema desta pesquisa se dá, portanto, pelos seguintes aspectos:

\begin{abstract}
a) Disponibilização de um modelo de avaliação de desempenho construtivista apto a apoiar a gestão da Asplan e indicar as áreas que merecem aperfeiçoamento $e$ ordená-las de acordo com o nível de potencial contribuição para a performance do setor;
\end{abstract}

b) Oportunidade de pesquisa decorrente da carência de apresentação de resultados decorrentes do desenvolvimento de um modelo de avaliação de desempenho que atenda aos requisitos da abordagem construtivista de avaliação de desempenho, no âmbito do setor público.

Diante disso, apresenta-se como questão de pesquisa que baliza este estudo: "Como construir um modelo de avaliação de desempenho construtivista para apoiar a gestão da Assessoria de Planejamento do Tribunal de Justiça de Santa Catarina?".

Esta pesquisa buscou, portanto, desenvolver um modelo de avaliação de desempenho, de acordo com a percepção e interesses do gestor. Tal modelo apresentou, ainda, informações necessárias à gestão organizacional no âmbito do contexto pesquisado, podendo ser aproveitado, portanto, para apoiar a decisão. Trata-se de modelo de avaliação específico e adequado exclusivamente ao 
contexto pesquisado.

Este estudo, contudo, apresenta somente os aspectos inerentes à Gestão Interna do contexto analisado.

A Metodologia Multicritério de Apoio à Decisão Construtivista (MCDA-C) foi o instrumento de intervenção escolhido para a construção do modelo de avaliação de desempenho para a Asplan e, inclusive, para a realização da interpretação dos dados levantados. A aludida metodologia foi adotada por permitir a identificação dos critérios relevantes para o decisor, tendo como objetivo principal gerar o conhecimento necessário para a compreensão dos aspectos importantes no âmbito do contexto e que necessitam ser considerados em um modelo de avaliação de desempenho (Bortoluzzi, Ensslin, \& Ensslin, 2011).

A forma de coleta de dados proposta pela MCDA-C dá-se por meio de entrevistas abertas que, conduzidas pelos pesquisadores, são entabuladas com a participação do gestor e de intervenientes por ele escolhidos.

Os resultados encontrados demonstraram: o desenvolvimento de um modelo de avaliação de desempenho específico para o contexto pesquisado; a apresentação de recomendações para o aprimoramento da performance do contexto pesquisado, permitindo a alocação racionalizada dos recursos do setor.

Como conclusão do estudo, foram alcançados os objetivos esperados mediante a demonstração do processo para desenvolvimento do modelo de avaliação construtivista para apoiar as decisões do gestor da Asplan. Ademais, foi constatada a possibilidade de replicar-se o processo para construção de modelo próprio para os demais setores que compõem o TJSC.

\section{FUNDAMENTAÇÃO TEÓRICA}

A avaliação de desempenho e o apoio à decisão

O campo denominado Apoio à Decisão foi desenvolvido com o intuito de auxiliar a obtenção de elementos esclarecedores às decisões, as quais, por sua vez, seriam tomadas quando se escolhe fazer ou não fazer alguma coisa, ou quando se escolhe fazê-las de alguma forma (Roy, 2013).

No entanto, raramente as decisões são tomadas por indivíduos singularmente. Isso porque, ainda que a responsabilidade possa ser de um indivíduo, a decisão geralmente será produzida como decorrência de uma interação entre as preferências individuais e de outros atores (Roy, 2013). Dessa forma, a tomada de decisão não pode ser completamente separada de um processo decisório.

Para um processo decisório, por sua vez, não podem ser estabelecidas etapas predeterminadas ou organizadas de maneira lógica para o desenvolvimento de um fluxo de decisão. A existência, o conteúdo e a sequência dessas etapas são diretamente afetadas pela influência exercida pelos atores do processo (Mintzberg, 1976).

Diante disso, a utilização de uma metodologia aplicada ao processo decisório buscaria alcançar ações ou processos melhorados (White, 1975). 
O Apoio à Decisão serviria, nesse contexto, para fornecer as condições mais favoráveis possíveis sobre dado comportamento, com o intuito de aumentar a coerência, por um lado, entre a evolução do processo decisório e, por outro, entre as metas e sistemas de valores operados pelos atores do processo. Seria, portanto, a ciência que procura desenvolver uma rede de conceitos, modelos, procedimentos e resultados capazes de formar estruturas e um coerente corpo de conhecimentos que atuem como chave para orientar a tomada de decisão e comunicar sobre o tema de acordo com determinados objetivos e valores (Roy, 1993).

A área científica denominada Apoio à Decisão incorporou conhecimentos e práticas da área de Avaliação de Desempenho, no intuito de evoluir na construção do conhecimento no decisor relativamente a aspectos que ele julga relevantes para sua tomada de decisão, dado um contexto específico (Barzilai, 2001, 2005; Roberts, 1979).

Sobre o tema, Barzilai (2005) afirma que a avaliação de preferências serve como base à teoria da decisão. No mesmo sentido, Keeney (1992) ratifica a importância de utilizar o tempo de tomada de decisão por meio da análise de valores que são importantes, em vez de, como era usualmente, focar na escolha de alternativas possíveis para a resolução de dado problema.

O desempenho, por sua vez, é comumente percebido como orientador da direção de preferência. É conceito que transpassa todas as áreas da sociedade e tem sido utilizado para avaliar o mérito e/ou a qualidade do esforço individual e/ou coletivo (Micheli
\& Mari, 2014). Não obstante, embora a Avaliação de Desempenho seja tema discutido com frequência, raramente é definido (Neely, Gregory, \& Platts, 1995).

Para Neely et al. (1995), a avaliação de desempenho refletiria, literalmente, o processo de quantificação da ação. Segundo os referidos autores, a avaliação corresponderia ao processo de quantificação ou medição, em $\mathrm{si}$, e as ações àquilo que levam ao aprimoramento do desempenho da empresa. Dessa forma, avaliar significaria comparar os resultados alcançados daqueles que foram planejados (Brandão \&Guimarães, 2001).

As preocupações com a mensuração do desempenho remontam há séculos, no entanto, somente no último século passaram a ter reconhecimento formal. Em 1927, a publicação do "Means of Measuring Municipal Government" (Ridley, 1927a) e do "Measuring Municipal Government" (Ridley, 1927b) representaram um marco no desenvolvimento da Avaliação de Desempenho no setor público, devido ao rigor científico apresentado às mensurações descritas (Williams, 2004).

A partir dos trabalhos de Ridley, o desenvolvimento da avaliação de desempenho como instrumento de gestão se generalizou. Porém, somente na década de 1940, ela passou a existir formalmente. Nos anos de 1930 (1932 a 1940), o "British Association for the Advancement of Science" debateu o problema do reconhecimento científico do uso de escalas de mensuração nas ciências sociais, nos moldes em que é realizado nas ciências físicas. A conclusão foi que, desde que o uso da escala respeite as propriedades do tipo de escala construída (nominais, ordinais, intervalo e razão), é possível men- 
surar as sensações humanas (Stevens, 1946; 1959).

Já a partir da década de 1960, com o acirramento da concorrência das empresas privadas e a maior cobrança por parte da sociedade das empresas públicas, observou-se uma proliferação de métodos de avaliação de desempenho (Giffhorn, 2011).

Posteriormente, verificou-se maior valorização da avaliação de desempenho, decorrente de uma mudança fundamental: a transcendência da fase de custos para a de valores nas organizações. Houve, portanto, uma mudança na percepção do que deve ser avaliado nas organizações, visando ao acompanhamento criterioso das coisas que efetivamente importam às empresas (Neely, 1999).

Para efeito desta pesquisa, foi adotada a definição de Avaliação de Desempenho como processo para construir conhecimento no decisor, no contexto específico que se propõe avaliar, a partir da percepção do próprio decisor. Tal processo busca identificar, organizar e mensurar, ordinal e cardinalmente, os aspectos reconhecidos como necessários e suficientes para a gestão do contexto, além de permitir visualizar gráfica e numericamente o impacto das ações e seu gerenciamento (Ensslin et. al., 2007). A adoção desse conceito deu-se em razão da expectativa de aplicabilidade do método ao contexto pesquisado e em especial por sua aderência à percepção dos problemas reais vivenciados pelos atores.

Esse entendimento da avaliação de desempenho tem conduzido nas últimas décadas a dezenas de aplicações práticas e cientí- ficas publicadas em periódicos internacionais qualificados (Ensslin, Ensslin, Dutra, \& Petri, 2007), (Ensslin, Giffhorn, Ensslin, Petri, \& Vianna, 2010), (Ensslin, Dutra, \& Ensslin, 2000), (Della Bruna, Ensslin, \& Ensslin, 2014); (Della Bruna, Ensslin, \& Ensslin, 2011), (Giffhorn, 2011), (Longaray \& Ensslin, 2015), (Longaray, Ensslin, Ensslin, \& Da Rosa, 2015), (Marafon, Ensslin, Lacerda, \& Ensslin, 2015), (Micheli \& Mari, 2014), (Rolim Ensslin, Ensslin, Back, \& Lacerda, 2013), (Tasca, Ensslin, Rolim Ensslin, \& Bernardete Martins Alves, 2010), (Tasca, Ensslin, \& Ensslin, 2012), (Zamcopé, Ensslin, \& Ensslin, 2012). De tais estudos, verifica-se a oportunidade de elicitação do desenvolvimento de modelos de avaliação de desempenho construtivistas no âmbito das organizações públicas brasileiras.

A metodologia multicritério de apoio à decisão - construtivista

Considerando a possibilidade de uso da avaliação de desempenho para o apoio à decisão, optou-se pela adoção de uma abordagem construtivista para o desenvolvimento do modelo de avaliação de desempenho para o contexto pesquisado.

Tal classificação é estabelecida por Roy (1993) e disciplina que, no que concerne aos resultados produzidos por meio de processos que visam ao apoio à decisão, os investigadores teriam trilhado três caminhos principais: o realismo, que se utiliza de descrições; o prescritivismo, que adota uma postura axiomática, e o construtivismo, que busca hipóteses de trabalho para posteriores recomendações.

Com fundamento na classificação proposta 
por Roy (1993), há quatro tipos de abordagem, no que tange à avaliação de desempenho: (i) normativista; (ii) descritivista; (iii) prescritivista; (iv) construtivista (Bortoluzzi et al., 2011; Ensslin et al., 2010, 2012; Tsoukiàs, 2008).

A abordagem normativista seria orientada pelo racionalismo (Ensslin, Montibeller, \& Noronha, 2001). Por meio dela, o pesquisador previamente seleciona as normas que o orientarão e pretende que o modelo tenha amplitude universal, ou seja, torne-se aplicável em diversos contextos (Tsoukiàs, 2008).

A abordagem descritivista, também fulcrada no racionalismo, por sua vez, deixa o pesquisador com a incumbência de identificar, no contexto físico a ser avaliado, as variáveis que influenciam o resultado desejado pelo decisor, com base em experiências de avaliação de desempenho realizadas em outros contextos (Ensslin, 2001; Tsoukiàs, 2008). Para essa abordagem, ao decisor recai, portanto, a aceitação das consequências do modelo, mediante a crença de que os resultados passados serão repetidos no futuro. (Ensslin et al., 2001).

As abordagens realistas mencionadas antes (normativista e descritivista) estão associadas ao processo de tomada de decisão. As duas abordagens que serão apresentadas afiliam-se ao processo de apoio à decisão (Tsoukiàs, 2008).

Para a abordagem prescritivista, as preocupações que fundamentam o modelo de avaliação emanam do decisor, ao longo de um processo de aprendizado que tem seu foco no facilitador. Mediante a convicção de que o decisor tem conhecimento suficiente sobre o seu problema, o facilitador seria responsável por conduzir o processo, buscando identificar, no discurso do decisor, as variáveis que devem integrar o modelo de avaliação (Azevedo et al., 2011; Marafon, Ensslin, Ensslin, \& Lacerda, 2012). Essa abordagem tem como fonte de dados central o decisor, todavia o conhecimento é construído no facilitador e dele advém a proposta das variáveis a serem avaliadas no contexto pesquisado.

A abordagem construtivista, por sua vez, defende que as variáveis constituintes do modelo de avaliação e suas escalas devem emergir do decisor (Bortoluzzi et al., 2011; Ensslin et al., 2010, 2012a). Contudo, diferentemente do prescritivismo, para essa abordagem, o facilitador reconhece que 0 decisor não tem conhecimento pleno acerca do problema, portanto deve ser apoiado em um processo de construção desse entendimento. O processo de desenvolvimento do conhecimento no decisor dá-se mediante a contextualização do problema e de possíveis soluções para ele, considerando o contexto específico pesquisado (Tsoukiàs, 2008).

Por meio da abordagem construtivista, pretende-se desenvolver no decisor, de forma interativa, um corpo de conhecimentos suficientes que possibilitem a compreensão da consequência das decisões nos aspectos que o próprio decisor julga necessários (Azevedo et al., 2011). Tal como ocorre na abordagem prescritivista, a fonte das variáveis consideradas no modelo é o próprio decisor, contudo, na abordagem construtivista, ele é detentor de um conhecimento ampliado com o apoio do facilitador e dos intervenientes. 
Por esse motivo, adotando-se uma abordagem construtivista, infere-se que que as variáveis constituintes do modelo de avaliação a ser desenvolvido, suas escalas e a integração delas devem emergir do decisor (Ensslin, Dutra, \& Ensslin, 2000; Ensslin et al., 2010, Bortoluzzi, Ensslin, \& Ensslin, 2011).

A Metodologia Multicritério de Apoio à Decisão - Construtivista (Multicriteria Decision Aid - Constructivist - MCDA-C) apresenta-se, portanto, como instrumento de apoio à decisão construtivista disponível aos gestores. Caracteriza-se como um processo inserido nas organizações, com o objetivo de fornecer informações necessárias e suficientes à tomada de decisão pelos gestores, de acordo com seus valores e preferências (Lacerda, Ensslin, \& Ensslin, 2011).

A utilização dessa metodologia favorece o estabelecimento de indicadores mais adequados à realidade das instituições públicas e oferta: priorização de ações pelo decisor; maior transparência à sociedade acerca das ações tomadas pelos gestores públicos, por meio da adoção de indicadores; melhor utilização dos recursos públicos, uma vez que evita possíveis desperdícios por intermédio do melhor direcionamento desses recursos, relativamente à estratégia do decisor (Lacerda et al., 2011).

A MCDA-C permite, portanto, a identificação dos critérios relevantes para o decisor, tendo como objetivo principal gerar o conhecimento necessário para a compreensão de quais aspectos são importantes no contexto específico pesquisado e que necessitam ser considerados em um modelo de avaliação de desempenho (Bortoluzzi et al., 2011).
Embora se considere que a origem da aludida metodologia tenha mais de dois séculos, sua consolidação ocorreu a partir da década de 1980. Apresentam-se como expoentes da MCDA-C os estudos de Roy (1996) e Landry (1995), que definem os limites da objetividade para os processos de apoio à decisão, de Skinner (1986) e Keeney (1992), que reconhecem que os atributos dos modelos de avaliação são específicos ao decisor em cada contexto, e de Bana e Costa (1993), que elicitam as convicções da metodologia, entre outros (Ensslin et al., 2010).

A MCDA-C divergiu das Metodologias Multicritério de Apoio a Decisão (MCDA) tradicionais, que buscariam uma solução ótima entre alternativas preexistentes, restringindo o apoio à decisão a uma etapa de formulação de alternativas e outra de decisão. Nesse sentido, têm-se os trabalhos de Zambon et al. (2005), Gomes (2005), Campos e Almeida (2006), entre outros (Ensslin et al., 2010). A objetividade pode-se apresentar como limitação para a MCDA-C, considerando as MCDA tradicionais. No entanto, tal limitação apresenta-se como inerente à adoção da abordagem construtivista de avaliação de desempenho como instrumento de apoio à decisão. Ao reconhecer que os problemas são singulares e que a contextualização dos problemas e os objetivos devem emergir do decisor (Tsoukiàs, 2008), infere-se que o resultado da MCDA-C seja específico para o gestor e para o contexto pesquisados.

Por fim, a referida metodologia pressupõe, ainda, que a atividade de apoio à decisão seja desenvolvida em três fases: estruturação, avaliação e recomendações, a serem descritas no item 4. 


\section{METODOLOGIA}

\section{Enquadramento metodológico}

Esta seção busca apresentar os procedimentos metodológicos adotados para a investigação do problema ora proposto, conforme a Figura 1.

Figura 1 - Enquadramento metodológico

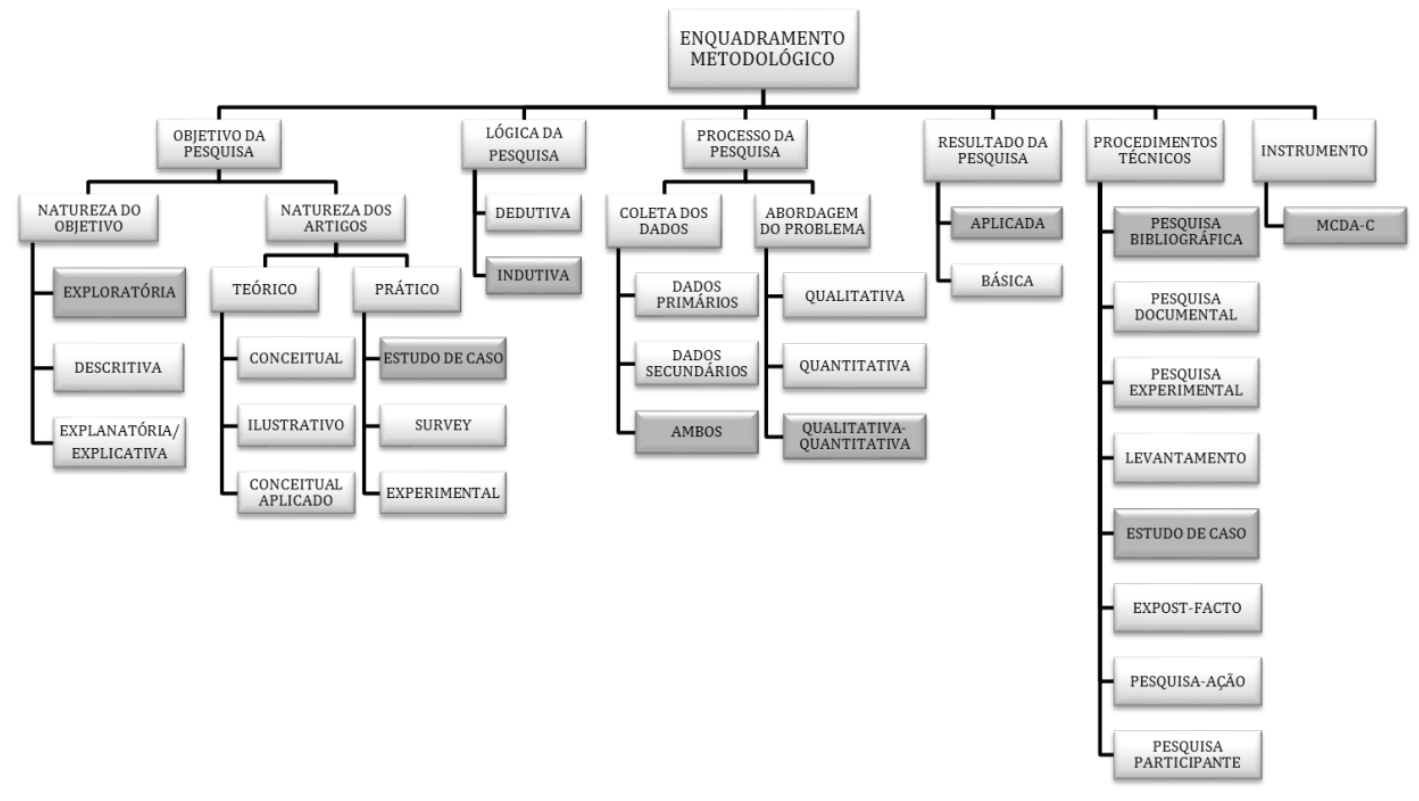

O contexto físico em que foi realizado o estudo de caso, denominado Asplan, foi escoIhido diante da demonstração de interesse do decisor daquele setor na adoção de uma metodologia que possibilite aos gestores aperfeiçoar o processo decisório e fomentando a participação ativa de outros atores do contexto. $O$ interesse do gestor apresenta-se como essencial ao sucesso da aplicação da metodologia, tendo em vista que a participação do decisor é inerente ao desenvolvimento da metodologia construtivista, como será evidenciado no item 4 , que trata dos resultados da pesquisa.

Conforme preconiza a MCDA-C, a fase de contextualização, posteriormente explicitada, permite a identificação dos atores do contexto a ser pesquisado. Esses atores são classificados como: decisor, que é responsável pela tomada de decisão; interveniente, que não tem poder de decisão, embora influencie o decisor; facilitador, que é compreendido como o consultor ou pesquisador que irá apoiar o processo decisório, e agido, que sofre o impacto das decisões tomadas.

O desenvolvimento do modelo de avaliação de desempenho construtivista é fundamentado na realização das entrevistas que contam com a participação do decisor, dos facilitadores e intervenientes e dos brainstormings (Bortoluzzi et al., 2011). Dessa forma, para a presente pesquisa, os facilitadores conduziram entrevistas abertas, realizadas com o decisor, e que contaram com a colaboração de dois intervenientes por ele escolhidos entre os Assessores de Planeja- 
mento atuantes no setor, conforme proposto pela MCDA-C.

A realização das entrevistas não estruturadas e de reuniões de brainstorming para o desenvolvimento do modelo de avaliação de desempenho ocorreram no período de fevereiro a maio de 2015. As entrevistas e reuniões foram conduzidas pelos facilitadores por meio de perguntas abertas que induziram o decisor a explicitar suas principais preocupações no que concerne à gestão do setor pesquisado. Os intervenientes atuaram, precipuamente, elucidando dúvidas do decisor a respeito do contexto e acrescentando informações aos aspectos abordados pelo decisor.

A utilização do método MACBETH permitiu a transformação de escalas cardinais em ordinais, também por meio da aferição de valores apresentados pelo decisor, em reuniões.

O detalhamento do desdobramento e a forma utilizados para a efetiva realização da coleta de dados podem ser verificados nos procedimentos para construção do modelo, detalhados em item próprio deste artigo.

Já a triangulação realizada para análise de dados permitiu combinar os métodos e fontes de coleta de dados obtidos, sendo que o modelo de avaliação de desempenho desenvolvido se apresenta como resultado de todas as entrevistas realizadas, de observação e notas de campo, e dos resultados obtidos com a utilização do método Macbeth.

Instrumento de intervenção adotado

A Metodologia Multicritério de Apoio à Deci- são Construtivista (MCDA-C) foi o instrumento de intervenção escolhido para desenvolver o modelo e, inclusive, para a realização da interpretação dos dados levantados. A escolha pela utilização da MCDA-C para a análise dos dados, no presente contexto, resulta da compreensão de que os processos sociais envolvem pessoas, valores e suas percepções, ou seja, são situações consideradas complexas por abarcarem múltiplos e conflitantes critérios (Roy \& Vanderpooten, 1997). A explicitação das fases inerentes e o detalhamento da MCDA-C será apresentada juntamente com os resultados da pesquisa.

\section{RESULTADOS DA PESQUISA}

Neste item, apresenta-se a aplicação da MCDA-C para o desenvolvimento de um modelo de avaliação de desempenho em um setor do Tribunal de Justiça de Santa Catarina, como resposta à pergunta de pesquisa proposta.

Embora o estudo tenha abrangido vários aspectos do contexto em referência, este estudo atém-se à análise do processo de construção do modelo, na condição de método de apoio à decisão para a gestão interna do setor.

Para o desenvolvimento do modelo de avaliação de desempenho, a MCDA-C propõe que a atividade de apoio à decisão seja desenvolvida em três fases:

\section{Fase de estruturação}

Destina-se à compreensão do problema e do contexto físico pesquisado. Por meio da identificação do problema, dos atores e da geração de conhecimento no decisor, busca- 


\section{AVALIAÇÃO MULTICRITÉRIO DE DESEMPENHO. O CASO DE UM TRIBUNAL DE JUSTIÇA}

-se representar as questões de interesse do gestor por meio de uma estrutura hierárquica de valor.

\section{Fase de avaliação}

Nela, por intermédio de um modelo matemático, intenta-se ordenar as alternativas propostas pelos atores envolvidos no processo de desenvolvimento do modelo, de acordo com a preferência do decisor entre os níveis de impacto dessas alternativas (Keeney, 1992).

\section{Fase de recomendações}

Nela, são propostas ações de aprimoramento da performance do setor pesquisado, em relação ao desempenho atual, além de se estabelecer a robustez do modelo construído, mediante a análise de sensibilidade (Keeney, 1992).

\section{Fase de estruturação}

Na primeira fase, estruturação, foram realizadas reuniões e entrevistas abertas, que contaram com a participação do decisor, intervenientes e facilitadores. Os encontros buscaram gerar conhecimento no decisor, por meio de discussões atinentes à compreensão do problema e do contexto pesquisado e à identificação do problema e dos atores. Como resultado dessa fase, obtém-se a representação das principais preocupações do decisor em uma estrutura hierárquica de valor.

\section{Contextualização}

A fase de contextualização implicou a identificação dos atores (decisor, facilitador, inter- venientes e agidos), na contextualização do problema, na evidenciação do rótulo (enunciado do problema) e na elaboração do sumário (apresentação do problema, justificativa de sua relevância, o que se propõe a fazer para solucionar o problema e o que se espera obter como resultados).

$\mathrm{Na}$ identificação dos atores para o contexto pesquisado, foi considerado decisor o Coordenador da Assessoria de Planejamento, ao tempo da pesquisa. Como intervenientes, três Assessores de Planejamento foram destacados pelo decisor; como facilitadores atuaram os pesquisadores; e foram considerados agidos, Assessores de Planejamento e servidores das áreas correlatas.

$\mathrm{Na}$ evidenciação do rótulo, o problema foi identificado como a necessidade verificada pelo Coordenador da Asplan de dispor de instrumento de apoio à decisão apto à realização do acompanhamento das atividades realizadas pelo setor e de disseminação das informações do que está sendo concretizado pelos diversos Núcleos, além da priorização das ações que impactem positivamente no desempenho da área e da organização.

Infere-se que tal necessidade decorre da escassez de recursos disponíveis, em especial no que se refere à força de trabalho da Assessoria. Dessa forma, esse projeto tem por objetivo o desenvolvimento de modelo de apoio à decisão construtivista que contemple as atividades sob a responsabilidade da Asplan.

Ao final do projeto, espera-se desenvolver um modelo que acompanhe as atividades realizadas pela Asplan e priorize os projetos do setor. Além disso, objetiva-se disponibili- 
zar instrumento apto a construir, fixar e disseminar conhecimentos e informações por meio de processo que identifica, organiza, mensura e integra os aspectos do contexto julgados relevantes pelo decisor. E que, ademais, meça em que grau os critérios escolhidos pelo decisor são alcançados, gerando procedimento que permita o aprimoramento do desempenho organizacional.

\section{Estrutura hierárquica de valor}

A construção da estrutura hierárquica, de outro norte, compreende a identificação dos Elementos Primários de Avaliação (EPAs), a construção dos conceitos decorrentes da análise dos EPAs e o agrupamento de tais conceitos, consoantes às áreas de preocupação, também denominadas objetivos estratégicos. Por fim, desenvolve-se a construção dos descritores, que compreende 0 desenvolvimento e a análise de mapas cognitivos, contemplando relações entre meio e fim; a transformação dos mapas cognitivos em estruturas arborescentes, e a definição de escalas ordinais de mensuração.

Na primeira etapa dessa fase, foram identificados 52 EPAs. Após essa identificação, foi proposta a expansão do entendimento sobre esses elementos, por meio da construção de conceitos.

Os conceitos, baseados nos EPAs, estabelecem a direção de preferência do decisor. Consistem no estabelecimento de um polo presente, que se almeja alcançar, e, por meio da definição do polo oposto psicológico, demonstram a consequência que se espera evitar ou minimizar (Azevedo et al., 2011).
Como a construção dos EPAs e dos conceitos ocorre em decorrência de brainstorming, é usual a evidenciação de conceitos redundantes ou que, posteriormente, verificam-se destoantes dos objetivos do decisor. Em ambos os casos, há a exclusão de tais conceitos, desde que os interesses do decisor permaneçam sendo refletidos no modelo.

Após essa etapa, com a releitura de todos os conceitos, o decisor, apoiado pelos facilitadores, refletiu sobre o contexto, de forma integral e definiu os objetivos estratégicos do setor, organizando-os em uma estrutura hierárquica, composta pelos conceitos que constituem cada um dos objetivos.

Em um segundo momento, foram elaborados mapas cognitivos para os objetivos estratégicos, sendo que os conceitos considerados estratégicos foram inscritos na parte superior do mapa e aqueles conceitos operacionais, na parte inferior. Pode-se concluir, portanto, que se buscou organizar a estrutura hierárquica com base na relação de causa e efeito vislumbrada entre os conceitos, na ótica do decisor, com o suporte dos facilitadores.

Nessa ocasião, inclusive, foram testados os objetivos no tocante à necessidade e à suficiência dos conceitos desenvolvidos. No que concerne à necessidade, o decisor, novamente com o apoio dos facilitadores, relacionou cada conceito a um objetivo (necessidade). No que tange à suficiência, nenhum conceito ficou sem objetivo estratégico relacionado.

Os objetivos estratégicos identificados na pesquisa, bem como os respectivos conceitos, estão demonstrados na Figura 2. 
Figura 2. Estrutura top-down do modelo de avaliação de desempenho e os conceitos a eles relacionados

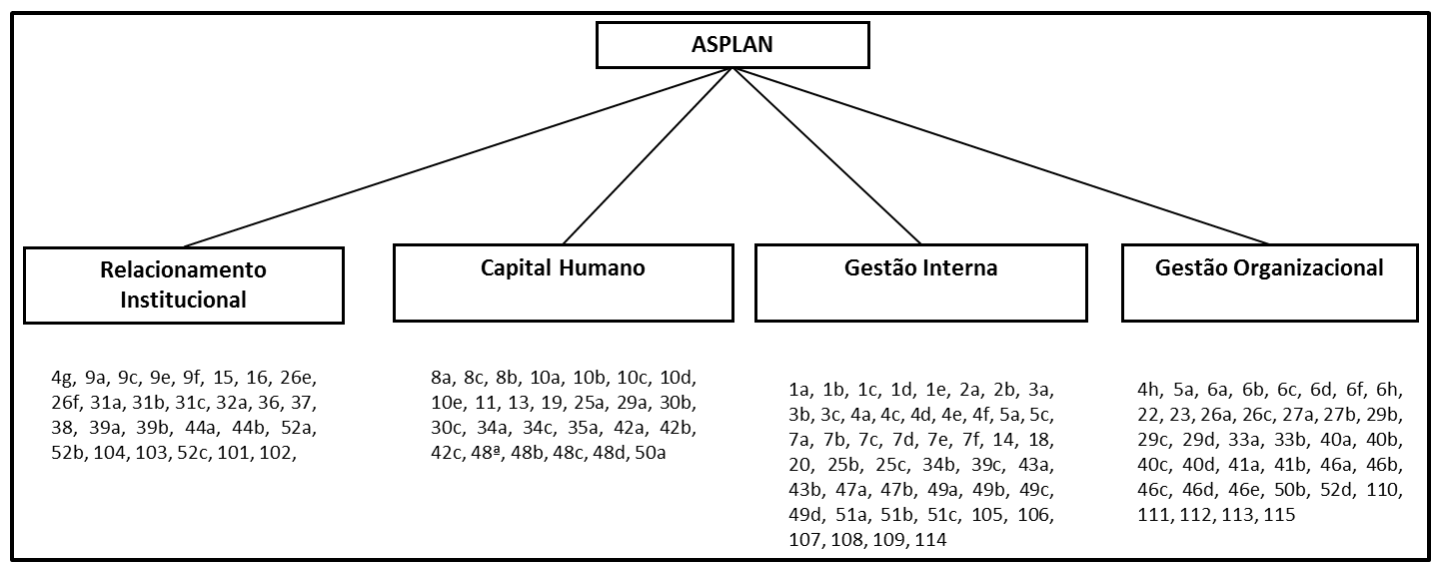

\section{Construção dos descritores}

O desenvolvimento dos mapas cognitivos, com a definição das relações estabelecidas entre os conceitos evidenciados, possibilitou a identificação de possíveis ações relacionadas aos interesses do decisor. A correlação dos conceitos evidenciou as relações entre meio e fim estabelecidas entre os conceitos meios, os conceitos estratégicos e os respectivos objetivos estratégicos, que po- dem ser identificadas por meio de clusters.

Buscando melhor elucidar o tema, a Figura 3 apresenta o mapa cognitivo de relações entre meio e fim para o objetivo "Gestão interna". Menciona-se que os conceitos com numeração superior a 100 foram construídos durantes as discussões inerentes ao desenvolvimento dos mapas cognitivos, ou seja, em momento posterior ao das entrevistas. 
Figura 3. Mapas de relações entre meio e fim para o objetivo estratégico "Gestão Interna Parte 1"

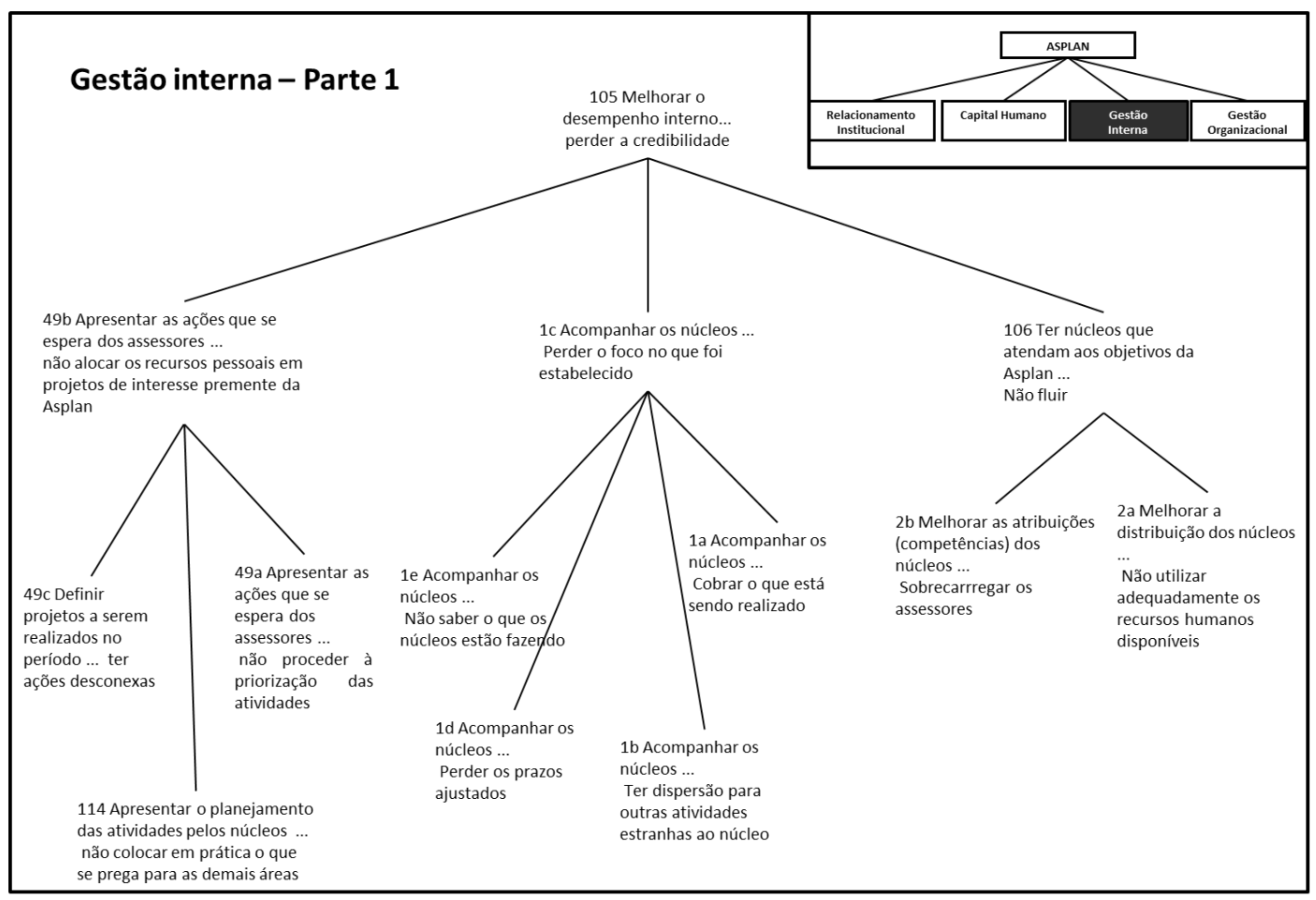

Com a construção dos mapas cognitivos, foram estabelecidas, por meio de uma estrutura hierárquica top-down, as relações entre meio e fim para todos os conceitos que constituem os objetivos estratégicos.

Após essa etapa, a MCDA-C propõe que esse conhecimento seja transportado para uma estrutura arborescente, denominada Estrutura Hierárquica de Valor. Nela, são identificados os Pontos de Vista Fundamentais (PVFs) e os Pontos de Vista Elementares (PVEs).

Para tanto, os clusters evidenciados no processo de conhecimento devem ser testados, como forma de validação de sua representatividade junto ao contexto pesquisado, com a finalidade de ser essencial, controlável, completo, mensurável, operacional, isolável, não redundante, conciso e compreensível (Keeney, 1992; Ensslin, Montibeller, \& Noronha, 2001; Azevedo et al., 2011).

Nesse sentido, com a evidenciação da Estrutura Hierárquica de Valor e com base nos elementos constantes no nível inferior de tal Estrutura, iniciou-se a construção dos descritores.

Os descritores propõem uma escala ordinal de medida, que associa os interesses abstratos propostos pelo decisor a outras propriedades do objeto. Trata-se de associação que, em geral, é realizada de forma complexa e que pode ser facilitada por meio da utilização de instrumentos científicos para sua realização (Keeney \& Raiffa, 1976; Keeney, 1992). A metodologia MCDA-C apresenta os mapas cognitivos para traduzir essas associações, 
pois permitem a evidenciação dos valores abstratos do decisor por meio da hierarquização dos conceitos fins (parte superior do mapa) (Azevedo et al., 2011).

Os descritores são definidos com base no conhecimento gerado no processo de desenvolvimento do modelo, podendo ser qualitativos, gráficos, pictóricos ou, mesmo, representados por símbolos alfanuméricos (Bana e Costa, Ensslin, Cornea, \& Vansnick, 1999; Dutra, Ensslin, Ensslin \& Lima, 2009). Não obstante, a ordem de preferência do desempenho com relação a cada descritor deve ser estabelecida de acordo com a percepção do decisor (Keeney \& Raiffa, 1976; Keeney, 1992).

Nesse contexto, a atividade de elaboração dos descritores é realizada por meio de escalas ordinais, construídas conjuntamente com o decisor, no intuito de que seja mensurado aquilo que ele considera efetivamente relevante para o critério analisado. Todos os conceitos que compõem um cluster devem ser considerados por ocasião da construção de determinado descritor.

Dessa forma, busca-se contemplar o efetivo interesse do decisor, não se atendo, portanto, à simples mensuração dos conceitos operacionais dos mapas cognitivos.

Após a definição da escala ordinal, foi proposta ao decisor a identificação dos níveis de referência para cada descritor: superior, que representa o nível que reflete a excelência do desempenho da organização, e inferior, representando o nível para o qual o desempenho é considerado comprometedor para a organização. O intervalo de desempenho compreendido entre o nível de excelência e o comprometedor é considerado normal (Azevedo et al., 2011).

A Estrutura Hierárquica de Valor referente ao PVF3 "Gestão Interna" contemplou seis descritores a ela relacionados, como evidencia o Quadro 1:

Quadro 1. Indicadores desenvolvidos para o PVF3 - "Gestão Interna"

\begin{tabular}{|c|}
\hline Indicadores desenvolvidos para o PVF3 - "Gestão Interna" \\
\hline GI05\% de processos de trabalho essenciais da Asplan (que só a Asplan realiza) mapeados e gerenciados na metodologia BPM \\
\hline GI06\% de projetos da Asplan executados com a metodologia de GP (com definição de etapas, prazos e responsáveis - papéis) \\
\hline GI07 Reunião para revisão da adequação das atribuiçães dos núcleos realizada no período de 6 meses \\
\hline GI01\% de núcleos com planejamento estabelecido e atualizado mensalmente \\
\hline GI04 Atualização mensal do mapa de priorização dos projetos da Asplan \\
\hline GI08 No de Projetos-piloto com a utilização de métodos e ferramentas de gestão inovadoras no PJSC (não consolidadas no PJSC), no \\
período de 12 meses \\
\hline
\end{tabular}

Fase de avaliação

A segunda fase da MCDA-C, denominada de avaliação, por sua vez, objetiva a integração do modelo de forma global, por meio da utilização de escalas cardinais. Ela pressupõe a realização das seguintes etapas:
Análise de independência; Construção das funções de valor; Identificação das taxas de compensação, e Identificação do perfil de impacto das alternativas. Nesse sentido, busca-se demonstrar o desenvolvimento da fase de avaliação nas seguintes subseções. 


\section{Análise de independência}

A análise de independência preconizada pela MCDA-C busca verificar se as taxas de compensação utilizadas para a integração do modelo de avaliação de desempenho em referência são constantes e, portanto, se são independentes do desempenho de outros descritores (Lacerda et al., 2011). Isso implica a verificação de que os Pontos de Vista sejam independentes entre si (Keeney \& Raiffa, 1976; Keeney, 1992), o que pode ser checado por meio da análise da propriedade de isolabilidade (Roy, 1996).

Para a realização dessa etapa, verificou-se se dado desempenho de um descritor não influencia na diferença de atratividade entre os níveis de outro. Após realizado esse teste com todos os descritores do modelo, observando-se a independência preferencial mútua (Keeney, 1992), concluiu-se que são preferencialmente independentes, tanto a forma ordinal quanto na cardinal.

Construção das funções de valor
Para realizar-se a integração do modelo de avaliação de desempenho, diante das diferentes escalas de medida utilizadas na construção dos descritores, é necessário fazer a transformação das escalas ordinais em cardinais.

Para determinar a função de valor, que possibilita a transformação da escala ordinal em cardinal, neste estudo, optou-se pela adoção do método Macbeth. Essa escolha se deu por seu reconhecimento científico e pela praticidade do processo.

Para a aplicação desse método, foi utilizado o software M-Macbeth, que permitiu a construção de uma matriz de julgamentos, constituída da intensidade da diferença de atratividade entre os níveis da escala ordinal para todos os descritores, na percepção do decisor.

A Figura 4 demonstra a transformação de uma escala ordinal em escala cardinal, para o descritor "GI01 - Percentual de núcleos com planejamento estabelecido e atualizado mensalmente". 
AVALIAÇÃO MULTICRITÉRIO DE DESEMPENHO. 0 CASO DE UM TRIBUNAL DE JUSTIÇA

Figura 4. Transformação da escala ordinal em escala ordinal, para o descritor GI01.

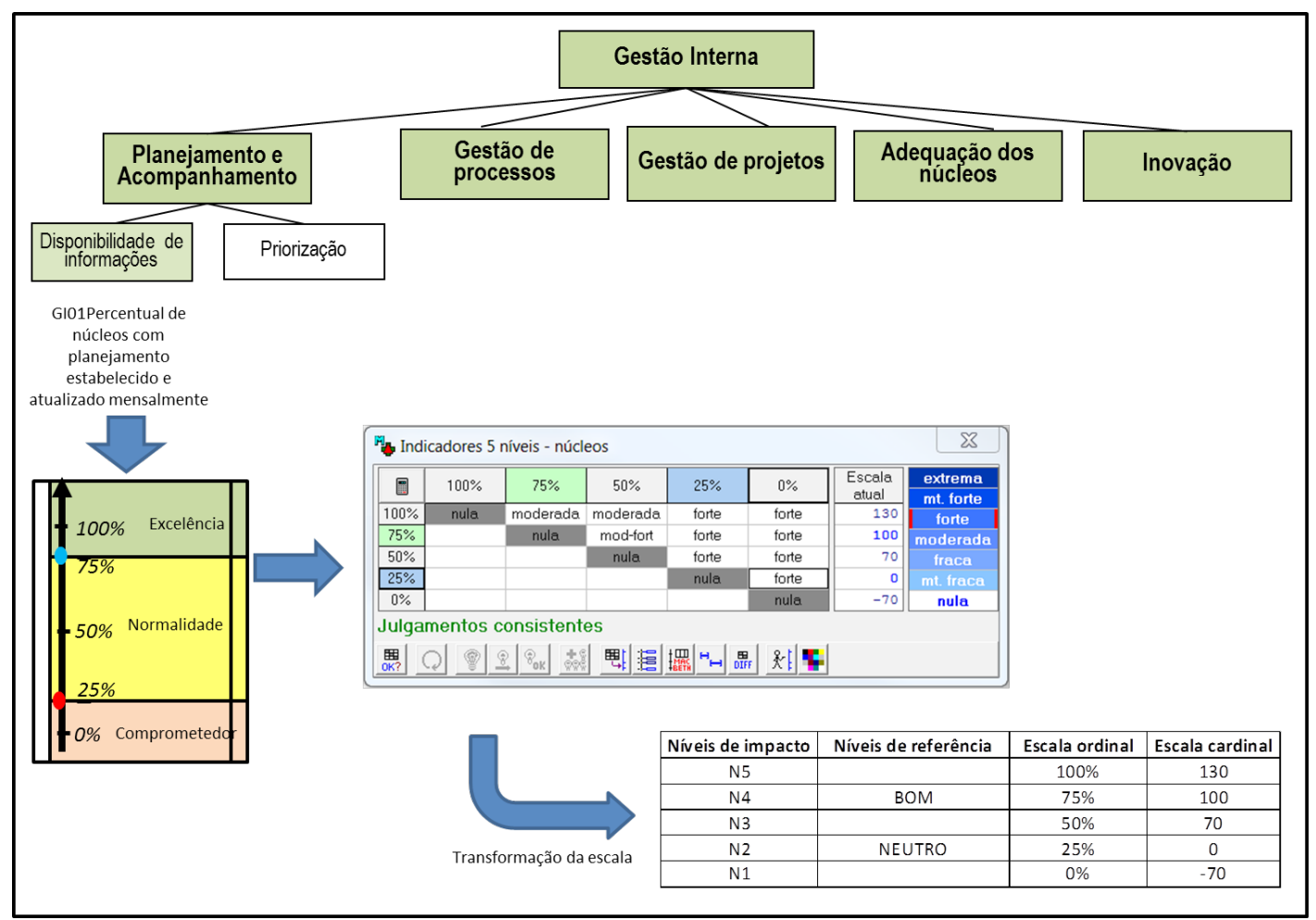

Fonte: elaborado pelos autores

Após a obtenção de escalas cardinais para todos os descritores, foi possível elaborar Estruturas Hierárquicas de Valor para todos os Pontos de Vista Fundamentais.

A Estrutura Hierárquica de Valor desenvol- vida para o PVF3 "Gestão Interna", contemplando os respectivos descritores, níveis do descritor - "a", níveis de normalidade e funções de valor - “f(a)", está ilustrada na Figura 5. 
Figura 5. Estrutura hierárquica de valor do PVF 3, "Gestão Interna", contemplando PVEs, descritores, níveis do descritor, níveis de normalidade e funções de valor

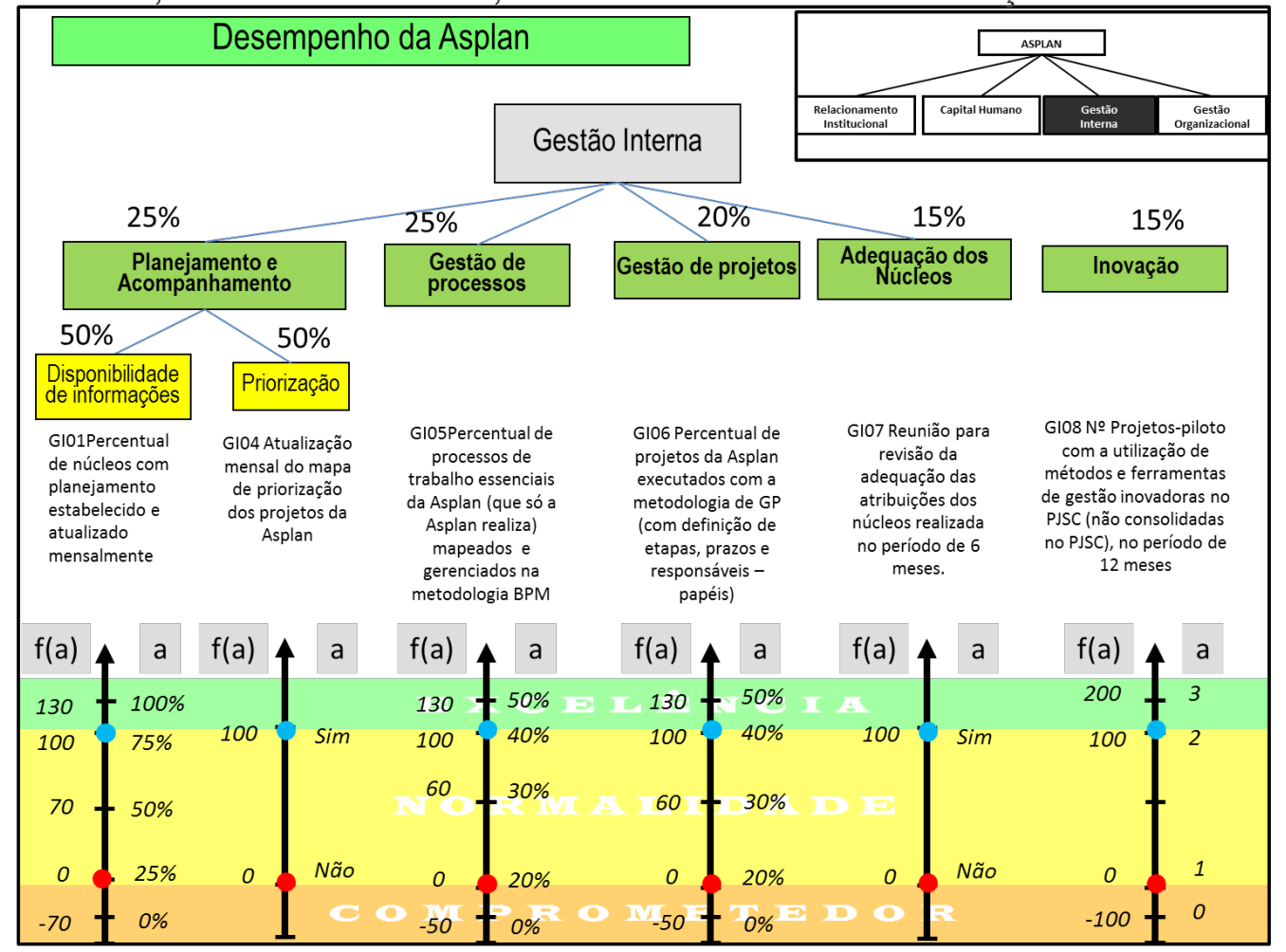

Fonte: elaborado pelos autores

Identificação das taxas de compensação

A construção da Matriz de Julgamentos, constituída das funções de valor de cada descritor, viabiliza a mensuração cardinal dos critérios considerados relevantes pelo decisor.

Todavia, para a integração do modelo de avaliação de desempenho, deve-se identificar qual é a contribuição de cada critério para o desempenho global do contexto ou, para o caso em estudo, para o desempenho da Asplan.

A MCDA-C propõe que a avaliação da contribuição de um descritor para o desempenho global do modelo de avaliação de desempenho seja realizada com a definição de taxas de compensação.
Identificação do perfil de impacto das alternativas

Após a conversão das escalas ordinais em cardinais e a definição das taxas de substituição, tornou-se viável a avaliação do desempenho global do contexto estudado. Essa avaliação foi realizada com a determinação do status quo, ou seja, por meio da coleta de informações referentes à medição de todos os descritores propostos. Dessa forma, aferiu-se o desempenho objetivamente alcançado pela Asplan para cada critério alvo de preocupação do decisor.

A avaliação global do contexto atual foi avaliada em 22 pontos, ou seja, uma avaliação global abaixo da normalidade. Um objetivo estratégico ficou dentro da normalidade: 
"Gestão Interna" com 40 pontos. Os demais objetivos apresentaram um desempenho comprometedor, sendo que o objetivo "Gestão organizacional" ficou com 67 pontos, "Relacionamento Institucional" com 27 pontos e "Capital humano" com 22 pontos.

Com essa expansão de entendimento proporcionado pela construção das taxas de compensação, foi possível ordenar os critérios de acordo com sua contribuição global, usando a seguinte equação:

$\Delta V_{\text {Good,Q }}\left(\right.$ Criterion $\left._{i}\right)=V_{\text {Good }}\left(\right.$ Criterion $\left._{i}\right)-V_{\text {Q }}\left(\right.$ Criterion $\left._{i}\right)$

\section{Onde:}

- $\Delta V_{\text {Good,Q }}\left(\right.$ Criterion $\left._{i}\right)=$ Incremento de desempenho do critério i ao passar do nível atual para o nível superior da normalidade.

- $V_{\text {Good }}\left(\right.$ Criterion $\left._{i}\right)=$ Mensuração Global quando o desempenho do Critério i estiver no nível superior da normalidade e os demais critérios no nível atual.

- $V_{\mathscr{Q}}\left(\right.$ Criterion $\left._{i}\right)=$ Mensuração Global quando o desempenho de todos os critérios do modelo apresentarem nível atual.

- $\mathrm{i}=1, \mathrm{n}$ Critérios do modelo

- $\mathrm{n}=$ Número de critérios do modelo

A determinação do status quo do objetivo "Gestão Interna" permitiu a identificação de pontos fortes e fracos do setor no que tange ao referido tema.

Da medição dos descritores, restou evidenciado que, dos seis descritores que compõem essa FPV3, dois apresentaram desempenho comprometedor, quais sejam: "GI05\% de processos de trabalho essenciais da Asplan (que só a Asplan realiza), mapeados e gerenciados na metodologia
BPM" e "GI06\% de projetos da Asplan executados com a metodologia de GP (com definição de etapas, prazos e responsáveis - papéis)".

É importante ser destacado que a maioria dos descritores desenvolvidos para 0 modelo de avaliação de desempenho da Asplan dependia de projetos para que fossem efetivamente viabilizados.

Diante desse contexto, a identificação do perfil de desempenho possibilitou a evidenciação e tradução de uma percepção inicial do decisor relativa à deficiência no acompanhamento das atividades e rotinas realizadas pelos núcleos que atuam no setor.

\section{Fase de recomendações}

Para a MCDA-C, a etapa de Recomendações não evidencia ações a serem tomadas, mas, de outro norte, intenta servir de apoio ao decisor para entabular ações e avaliar as consequências da implementação dessas ações em face dos objetivos estratégicos da organização (Azevedo et al., 2011). Essa fase é subdividida em duas etapas: Análise de Sensibilidade e Elaboração de Recomendações.

\section{Análise de sensibilidade}

A análise de sensibilidade compreende a atividade de analisar o impacto global da alteração de uma taxa de substituição ou se a medida de desempenho de algum critério pode ser alterada com a modificação da taxa de substituição de uma PVF ou PVE. Cabe ressaltar que não é função da etapa de Recomendações definir ações, mas sim servir de apoio para ajudar o 
decisor a construir ações e avaliar suas consequências.

\section{Elaboração de recomendações}

Partindo-se do status quo apresentado pelo modelo de avaliação global desenvolvido, foram identificados os PVFs com pior desempenho. Não obstante, a aplicação da MCDA-C possibilitou a elaboração de modelo de avaliação de desempenho apto a demonstrar para o decisor: (i) os critérios que necessitam de intervenção; (ii) 0 processo de geração de ações para originar o aperfeiçoamento; (iii) a visualização das implicações da implantação em nível local e/ou operacional (no PVE), tático (PVF) e estratégico (Global) (Ensslin et al., 2010).

No que tange aos descritores da FPV de "Gestão Interna", ficou evidenciado que um descritor mereceria, de forma premente, Plano de Ações para a melhoria da performance do setor, pois foi identificado entre os cinco descritores do modelo de avaliação de desempenho com maior oportunidade de contribuição para 0 desempenho organizacional. O Quadro 2 apresenta os descritores propostos para a FPV3, "Gestão Interna", ordenados em razão daqueles que, com o implemento de ações de melhoria, mais impactariam no desempenho do contexto pesquisado.

Quadro 2. Critérios priorizados de acordo com a oportunidade de contribuição para a FPV3 "Gestão Interna".

\begin{tabular}{|c|c|c|c|c|c|}
\hline Cod & Objetivo $\quad \boldsymbol{\nabla} \mathbf{T}$ & Descrição Indicador & Situação atual & SQ Cardinal & oportunidade \\
\hline GI05 & Gestão Interna & $\begin{array}{l}\text { GI05 \% de processos de trabalho essenciais da Asplan (que só a Asplan } \\
\text { realiza) mapeados e gerenciados na metodologia BPM }\end{array}$ & 0 & -50 & 9,4 \\
\hline GI06 & Gestão Interna & $\begin{array}{l}\text { GI06 \% de projetos da Asplan executados com a metodologia de GP (com } \\
\text { definição de etapas, prazos e responsáveis - papéis) }\end{array}$ & 0 & -50 & 7,5 \\
\hline GI07 & Gestão Interna & $\begin{array}{l}\text { GI07 Reunião para revisão da adequação das atribuições dos núcleos } \\
\text { realizada no período de } 6 \text { meses }\end{array}$ & 0 & 0 & 3,8 \\
\hline GI01 & Gestão Interna & $\begin{array}{l}\text { GI01\% de núcleos com planejamento estabelecido e atualizado } \\
\text { mensalmente }\end{array}$ & 75 & 100 & 0,0 \\
\hline GI04 & Gestão Interna & GI04 Atualização mensal do mapa de priorização dos projetos da Asplan & 1 & 100 & 0,0 \\
\hline GI08 & Gestão Interna & $\begin{array}{l}\text { GI08 № de Projetos-piloto com a utilização de métodos e ferramentas de } \\
\text { gestão inovadoras no PJSC (não consolidadas no PJSC), no período de } 12 \\
\text { meses }\end{array}$ & 3 & 200 & $-3,8$ \\
\hline
\end{tabular}

Fonte: elaborado pelos autores

Dessa forma, o desenvolvimento do modelo de avaliação de desempenho construtivista para a Asplan evidenciou a possibilidade de utilização do processo no âmbito do setor público. No mesmo sentido, a pesquisa inova com a finalidade de apresentar os decorrentes da aplicação de um método de avaliação de desempenho no contexto público, não se atendo ao aspecto teórico relativo ao tema.

Percebe-se, ainda, que o principal resultado alcançado, que corresponde ao modelo de avaliação de desempenho desenvolvido, é único e apresenta a limitação de estar alinhado aos interesses específicos do decisor atual do setor pesquisado (Tsoukias, 2008). Nesse contexto, dificilmente poderá ser re- 


\section{AVALIAÇÃO MULTICRITÉRIO DE DESEMPENHO. 0 CASO DE UM TRIBUNAL DE JUSTIÇA}

petido, considerando que isso implicaria a substituição do contexto ou do decisor.

As principais contribuições percebidas do estudo referem-se à disponibilização de instrumento apto a identificar os critérios merecedores de atenção pelo setor e que mais impactariam seu desempenho. No mesmo passo, foram disponibilizadas aos servidores do setor informações relativas aos aspectos compreendidos como relevantes ao gestor e o indicativo das áreas que mereceriam ações prementes.

Não obstante, percebeu-se a viabilidade de replicar o procedimento para a construção de modelo de avaliação próprio para os demais setores que compõem o TJSC, comunicando os temas de interesse dos gestores públicos e permitindo avaliar o desempenho de outros contextos, portanto identificar os quesitos que mereceriam ser priorizados pelos setores para o aprimoramento do desempenho organizacional.

Considerando o encerramento do projeto, verificou-se que a pesquisa permitiu demonstrar um processo para o desenvolvimento de um modelo de avaliação de desempenho para apoiar a Asplan, por meio da utilização da MCDA-C. Infere-se, ainda, que o modelo desenvolvido com fulcro nas diversas fontes pesquisadas, evidenciou-se apto à ampliação do conhecimento do contexto em questão pelo decisor, bem como possibilitou a identificação dos quesitos a serem atendidos por futuros projetos desenvolvidos pelos Núcleos que compõem a Asplan, propiciando a melhoria da performance do setor e a alocação adequada dos escassos recursos.
Por esse motivo, os resultados confirmaram a teoria apresentada, que trata da possibilidade de acolhimento da avaliação de desempenho como ferramenta de apoio à decisão (Barzilai, 2005; Bortoluzzi et al., 2011; Ensslin et al., 2010b, 2012b; Tsoukiàs, 2008).

Para pesquisas futuras, evidenciaram-se as oportunidades de: 1) analisar o desempenho do setor em face do desempenho de outros contextos similares, encontrados no setor público brasileiro, como forma de combater a principal limitação deste estudo, correspondente à personalização do contexto a partir do ponto de vista do decisor; 2) analisar a utilidade do modelo de avaliação de desempenho desenvolvido, no âmbito do apoio à decisão do gestor da Asplan, com a possibilidade de proposição de aprimoramentos ao modelo.

\section{CONCLUSÕES}

Esta pesquisa buscou demonstrar o estudo de caso realizado em um setor do Tribunal de Justiça de Santa Catarina, com vistas ao desenvolvimento de um modelo de avaliação de desempenho construtivista para apoiar a gestão do aludido setor.

A MCDA-C foi utilizada como instrumento de intervenção para o contexto pesquisado, adstrito ao setor público. A opção pela metodologia deu-se em razão da perspectiva de desenvolvimento de um modelo de avaliação de desempenho apto a identificar, mensurar e integrar os aspectos considerados relevantes à percepção do decisor. Ainda, por possibilitar a avaliação global do contexto analisado e a demonstração dos quesitos que demandariam priorização, de acordo com sua oportunidade de contribuição para 
o desempenho global do setor.

Destacam-se como resultados da pesquisa: (i) o desenvolvimento de um modelo de avaliação de desempenho específico para o contexto da Asplan; (ii) a evidenciação de quatro Pontos de vistas fundamentais (PVFs) para o modelo de avaliação de desempenho da Asplan; (iii) a construção de seis descritores para o PVF "Gestão Interna", que abrangem todos os quesitos compreendidos pelo decisor como relevantes sobre o tema; (iv) após a aferição do status quo dos indicadores, a identificação de que um dos indicadores da PVF "Gestão Interna" mereceria priorização, considerando a melhoria de desempenho que oportunizaria para 0 desempenho do setor; (v) a verificação de que o modelo construído permite subsidiar o gestor no processo de tomada de decisão no que se refere à gestão do desempenho de seu setor; (vi) do desenvolvimento do modelo de avaliação de desempenho para um contexto menor, infere-se a viabilidade de replicar o procedimento para construção de modelo próprio para os demais setores que compõem o TJSC.

O desenvolvimento do modelo de avaliação de desempenho, principal resultado da pesquisa, permitiu construir conhecimento no decisor e nos intervenientes e facilitadores que atuaram no projeto. Ademais, proporcionou a representação das questões de interesse do gestor por meio de uma estrutura hierárquica de valor, que permitiu a elicitação dos indicadores a serem priorizados e aprimorados para a melhoria da performance do setor.

Ressalta-se que todas as fases e etapas do desenvolvimento do modelo de avaliação de desempenho contaram com a legitimação do decisor. Essa característica inerente à aplicação da MCDA-C, inclusive, implica o reconhecimento de que o modelo foi desenvolvido para o contexto específico da Assessoria de Planejamento, setor do Tribunal de Justiça de Santa Catarina, não sendo recomendado, portanto, a sua utilização em outros contextos, ainda que semelhantes.

Por fim, apresentaram-se como oportunidades para pesquisas futuras: (i) a análise do desempenho do setor em face do desempenho de outros contextos similares, encontrados no setor público brasileiro; (ii) a análise da utilidade do modelo de avaliação de desempenho da Asplan, com a possibilidade de proposição de aprimoramentos ao modelo.

\section{REFERÊNCIAS}

Azevedo, R. C., Ensslin, L., Lacerda, R. T. de O., França, L. A., Ibarra González, C. J., Jungles, A. E., \& Ensslin, S. R. (2011). Avaliação de desempenho do processo de orçamento: Estudo de caso em uma obra de construção civil. Ambiente Construído, 11(1), 85-104. doi:10.1590/S1678-86212011000100007

Bana e Costa, C. A. (1993). Três convicções fundamentais na prática do apoio à decisão. Pesquisa Operacional, 13, 1-12.

Bana e Costa, C. A., Ensslin, L., Cornea, E. C., \& Vansnick, J-C. (1999). Decision Support Systems in action: Integrated application in a multicriteria decision aid process. European Journal of Operational Research, 113(2), 315-335. doi:10.1016/S0377-2217(98)002197 
Barzilai, J. (2001). On the foundations of measurement. In: Proceedings of the 2001 IEEE International Conference on Systems, Man and Cybernetics, Tucson, 7-10 October 2001. 401-406.

Barzilai, J. (2005). Measurement and preference function modelling. International Transactions in Operational Research, 12(2), 173183. doi:10.1111/j.1475-3995.2005.00496.x

Bortoluzzi, S. C., Ensslin, S. R., \& Ensslin, L. (2011). Avaliação de desempenho multicritério como apoio à gestão de empresas: aplicação em uma empresa de serviços. Gestão e Produção, 18(3), 633-650. doi:10.1590/ S0104-530X2011000300014

Brandão, H. P., \& Guimarães, T. D. A. (2001). Gestão de competências e gestão de desempenho: Tecnologias distintas ou instrumentos de um mesmo construto? RAE-Revista de Administração de empresas, 41(1), 8-15. doi:10.1590/S0034-75902001000100002

Campos, V. R., \& Almeida, A. T. de. (2006). Modelo multicritério de decisão para localização de Nova Jaguaribara com VIP analysis. Pesquisa Operacional, 26(1), 91-107. doi:10.1590/S0101-74382006000100005

Catelli, A., \& Santos, E. S. (2004). Mensurando a criação de valor na gestão pública. RAP-Revista de Administração Pública, 38(3), 423-a.

Della Bruna Jr, E., Ensslin, L., \& Rolim Ensslin, S. (2014). An MCDA-C application to evaluate supply chain performance. International Journal of Physical Distribution \& Logistics Management, 44(7), 597-616. doi:10.1108/ijpdlm-05-2012-0157
Della Bruna, E., Ensslin, L., \& Ensslin, S. R. (2011, June). Supply chain performance evaluation: a case study in a company of equipment for refrigeration. In Technology Management Conference (ITMC), 2011 IEEE International (pp. 969-978). IEEE.

Dutra, A., Ensslin, L., Ensslin, S. R., Lima, M. V. A., \& Lopes, A. L. M. (2009). Inovação no processo de avaliação do desempenho organizacional: o uso da dimensão integrativa. RAl-Revista de Administração e Inovação, 5(2), 150-163. doi:10.5585/rai.v5i2.244

Dutra, A., Ensslin, S. R., Ensslin, L., \& Lima, M. V. A. (2010). A incorporação da dimensão integrativa nos processos de avaliação do desempenho organizacional: Um estudo de caso. Revista Contemporânea de Contabilidade, 6(11), 109-136. doi:10.5007/2175$-8069.2009 v 6 n 11 p 109$

Ensslin, L., Dutra, A., \& Ensslin, S. R. (2000). MCDA: A constructivist approach to the management of human resources at a governmental agency. International Transactions in Operational Research, 7(1), 79-100. doi:10.1111/j.1475-3995.2000.tb00186.x

Ensslin, L., \& Ensslin, S. R. (2007). Avaliação de desempenho: Objetivos e dimensões. I Seminário de Avaliação de Desempenho do Setor Público. Florianópolis: Secretaria Planejamento, G. D. S.

Ensslin, L., Ensslin, S. R., \& Pacheco, G. C. (2012). Um estudo sobre segurança em estádios de futebol baseado na análise bibliométrica da literatura internacional. Perspectivas em Ciência da Informação, 17(2), 71-91. 
Ensslin, L., Giffhorn, E., Ensslin, S. R., Petri, S. M. Vianna, W. B. (2010). Avaliação do Desempenho de Empresas Terceirizadas com o Uso da Metodologia Multicritério de Apoio à Decisão - Construtivista. Revista Pesquisa Operacional, 30(1), 125-152. doi:10.1590/ S0101-74382010000100007

Ensslin, L., Montibeller, N. G., \& Noronha, S. M. (2001). Apoio à decisão: Metodologias para estruturação de problemas e avaliação multicritério de alternativas. Florianópolis, SC: Insular.

Filgueiras, F. (2009). A tolerância à corrupção no Brasil: Uma antinomia entre normas morais e prática social. Opinião Pública, 15(2), 386-421. doi:10.1590/S010462762009000200005

Giffhorn, E. (2011). Modelo multicritério para apoiar o uso de avaliações de desempenho com foco nos indicadores. Tese (Doutorado). Programa de Pós-graduação em Engenharia de Produção, Universidade Federal de Santa Catarina, Florianópolis, SC.

Gomes, C. F. S. (2005). Using MCDA methods THOR in an application for outranking the ballast water management options. Pesquisa Operacional, 25(1), 11-28. doi:10.1590/ S0101-74382005000100002

Keeney, R. L., \& Raiffa, H. (1976). Decisions with multiple objectives: Preferences and value trade-offs. New York, USA: John Wiley \& Sons.

Keeney, R. L. (1992). Value-focused thinking: A path to creative decision making. Cambridge, UK: Harvard University Press.
Lacerda, R. T. de O., Ensslin, L., \& Ensslin, S. R. (2011). Contribuições à gestão estratégica de organizações quando analisados na visão de seu desempenho. Gestão Organizacional, 9(2), 327-358.

Landry, M. (1995). A note on the concept of 'problem. Organization Studies, 16(2), 315343. doi:10.1177/017084069501600206

Longaray, A. A., \& Ensslin, L. (2015). Use of multi-criteria decision aid to evaluate the performance of trade marketing activities of a Brazilian industry. Management and Organizational Studies, 2(2), 15-31. doi:10.5430/ mos.v2n2p15

Longaray, A. A., Ensslin, L., Ensslin, S. R., \& da Rosa, I. O. (2015). Assessment of a Brazilian public hospital's performance for management purposes: A soft operations research case in action. Operations Research for Health Care, 5, 28-48. doi:10.1016/j. orhc.2015.05.001

Marafon, A. D., Ensslin, L., Ensslin, S. R., \& Lacerda, R. T. (2012). Revisão sistêmica da literatura sobre avaliação de desempenho na gestão de P\&D. Revista Gestão Industrial, 8(3), 1-43. doi:10.3895/s180804482012000300001

Marafon, A. D., Ensslin, L., Lacerda, R. T. D. O., \& Ensslin, S. R. (2015). The effectiveness of multi-criteria decision aid methodology: A case study of R\&D management. European Journal of Innovation Management, 18(1), 86-109. doi:10.1108/EJIM-10-2013-0106

Micheli, P., \& Mari, L. (2014). The theory and practice of performance measurement. Ma- 
nagement Accounting Research, 25(2), 147-156. doi:10.1016/j.mar.2013.07.005

Mintzberg, H. (1976). Planning on the left side and managing on the right. Harvard Business Review, 7. Recuperado de https:// hbr.org/

Moisés, J. A. (2005). A desconfiança nas instituições democráticas. Opinião Pública, 11(1), 33-63. doi:10.1590/S010462762005000100002

Motta, P. R. de M. (2013). O Estado da arte da Gestão Pública. RAE-Revista de Administração de Empresas, 53(1), 82-90. doi:10.1590/ S0034-75902013000100008

Neely, A. (1999). The performance measurement revolution: Why now and what next? International Journal or Operations \& Production Management, 19(2), 205-228. doi:10.1108/01443579910247437

Neely, A., Gregory, M., \& Platts, K. (1995). Performance measurement system design: A literature review and research agenda. International Journal of Operations \& Production Management, 15(4), 80-116. doi:10.1108/01443579510083622

Ridley, C E. (1927a). Means of measuring municipal government. Doctoral dissertation, Syracuse University, Syracuse, New York, USA.

Ridley, C E. (1927b). Measuring municipal government. New York, USA: Municipal Administration Service \& School of Citizenship \& Public Affairs.

Roberts, F. S. (1979). Measurement theory,
Encyclopedia of Math, vol. 7: Addison-Wesley, Reading, MA.

Roy, B. (1993). Decision science or decision-aid science? European Journal of Operational Research, 66(2), 184-203. doi:10.1016/0377-2217(93)90312-B

Rolim Ensslin, S., Ensslin, L., Back, F., \& Lacerda, R., T. de O. (2013). Improved decision aiding in human resource management: $\mathrm{A}$ case using constructivist multi-criteria decision aiding. International Journal of Productivity and Performance Management, 62(7), 735-757. doi:10.1108/IJPPM-04-2012-0039

Roy, B. (1996). Multicriteria methodology for decision aiding. Dordrecht, Holanda: Kluwer Academic.

Roy, B. (2013) Multicriteria methodology for decision aiding. (Vol. 12) Springer Science \& Business Media.

Roy, B., \& Vanderpooten, D. (1997). An overview on The European school of MCDA: Emergence, basic features and current works. European Journal of Operational Research, 99(1), 26-27. doi:10.1016/S03772217(96)00379-7

Skinner, W. (1986). The productivity paradox. Harvard Business Review, 75. Recuperado de https://hbr.org/

Stevens, S. S. (1946). On the theory of scales of measurement. Science, 103(2684), 677-680. doi:10.1126/science.103.2684.677.

Stevens, S. S. (1959). Measurement, psychophysics, and utility. In: Churchman, C.W\& Ratoosh, P. (Eds), Measurement: Definitions 
and Theories. New York, USA: John Wiley.

Tasca, J.E., Ensslin, L., \& Ensslin, S. R. (2012). Evaluation of training programs: A case study in public administration. RAP-Revista de Administração Pública, 46(3), 647-675. doi:10.1590/S0034-76122012000300002

Tasca, J. E., Ensslin, L., Rolim Ensslin, S., \& Bernardete Martins Alves, M. (2010). An approach for selecting a theoretical framework for the evaluation of training programs. Journal of European Industrial Training, 34(7), 631-655. doi:10.1108/03090591011070761

Tsoukiàs, A. (2008). From decision theory to decision aiding methodology. European Journal of Operational Research, 187(1), 138-161. doi:10.1016/j.ejor.2007.02.039

White, D. J. (1975). Decision methodology. Wiley Chichester.
Williams, D. W. (2004). Evolution of performance measurement until 1930. Administration \& Society, 36(2), 131-165. doi:10.1177/0095399704263473

Zambon, K. L., Carneiro, A. A. de F. M., Silva, A. N. R. da., \& Negri, J. C. (2005). Análise de decisão multicritério na localização de usinas termoelétricas utilizando SIG. Pesquisa Operacional, 25(2), 183-199. doi:10.1590/ S0101-74382005000200002

Zamcopé, F. C., Ensslin, L., \& Ensslin, S. R. (2012). Construction of a model for corporate sustainability assessment: a case study in the textile industry. Gestão \& Produção, 19(2), 303-321. doi:10.1590/S0104$-530 \times 2012000200006$ 